\title{
MODEL OPTIMISASI NONLINIER JARINGAN PIPA GAS DENGAN PERCABANGAN
}

(Non-Linear Optimization Model for Gas Transmission System with Branch)

\author{
Francis Y Rumlawang \\ Jurusan Matematika FMIPA Universitas Pattimura Ambon \\ Jl. Ir. M. Putuhenam, Kampus Unpatti, Poka-Ambon \\ E Mail: fyr0617@yahoo.com
}

\begin{abstract}
Gas transmission system has a branch to costumer area that affects to flow rate, gas pressure, and pipe diameter. This paper discusses optimization of this transmission system. Optimum gas pressure and pipe diameter was found by minimizing cost objective function subjects to panhandle A and panhandle B constrain function. Steepest Descent method which is combined with Rangekutta methods is use to determine the optimization process. The result shows that the pipe branches affect the optimization variables.
\end{abstract}

Keywords: Objective function, panhandle A, panhandle B, stepest descent

\section{PENDAHULUAN}

Indonesia adalah negara penghasil gas terbesar di dunia namun kenyataannya Indonesia belum menikmati statusnya tersebut, akibat dari kenyataan bahwa harga gas masih relatif lebih mahal, dari sumber energi lainnya. Salah satu penyebab harga yang masih relatif tinggi adalah kurangnya sarana transportasi yang memadai dan murah untuk mendistribusikan gas agar sampai ke konsumen, karena pada umumnya sumber gas berada cukup jauh dari konsumen.

Dalam proses pendistribusian, alat transportasi yang paling aman dan efektif bagi gas adalah melalui jaringan pipa transmisi. Namun membangun jaringan pipa gas merupakan investasi yang sangat mahal dan membutuhkan perencanaan dan perhitungan yang baik.

Pembangunan dan pengoperasian jaringan pipa transmisi gas yang memenuhi kualitas dan standar keamanan yang baik, dipengaruhi oleh dua faktor. Pertama faktor ekonomi, yang dalam hal ini adalah biaya. Biaya tersebut meliputi biaya investasi, biaya operasi, dan biaya penambangan gas. Biaya investasi terdiri dari biaya pipa dan biaya kompresor. Biaya operasi adalah biaya pengoperasian pipa transmisi dan kompresor. Sebenarnya biaya untuk membeli pipa dapat dibuat minimum dengan memilih pipa berdiameter kecil, tetapi akan mengakibatkan kehilangan tekanan yang cukup besar, sehingga diperlukan kompresor dengan daya yang cukup besar. Akibatnya biaya investasi untuk pembelian kompresor akan naik. Sebaliknya biaya investasi dengan pipa berdiameter besar cukup mahal, namun biaya kompresor lebih murah. Kedua faktor teknis, meliputi kekuatan pipa, keamanan, lokasi jaringan pipa (darat dan laut),dan karakteristik dari gas (tekanan, temperatur,laju alir, viskositas gas, dan sebagainya).

Karena permasalahan utama kita disini adalah biaya dimana komponen utama dipengaruhi oleh diameter, tekanan dan flowrate, maka tujuan dari penulisan ini adalah membuat model untuk menghitung ukuran diameter yang optimum, serta distribusi tekanan dan flowrate gas sehingga biaya investasi dan operasi minimum, dengan menggunakan fungsi kendala
Panhandle A dan Panhandle B, yang diimplementasikan pada jaringan pipa transmisi dengan percabangan.

\section{Model Laju Alir Gas dan Biaya}

Misalkan konsumen berada pada suatu lokasi, namakan $\mathrm{L}$ dan $\mathrm{Q}$, sedangkan gas yang dikirim ke $\mathrm{L}$ dan Q melalui daerah A, B, C,.. ,K. Gas dari A ke L dikirim melalui jaringan pipa transmisi A-B, B-C,..., K-L serta ke $\mathrm{Q}$ melalui transmisi A-B, B-C,...,G-Q, dengan demikian terlihat bahwa terdapat percabangan di $G$, lebih jelas dapat dilihat dalam gambar 1 .

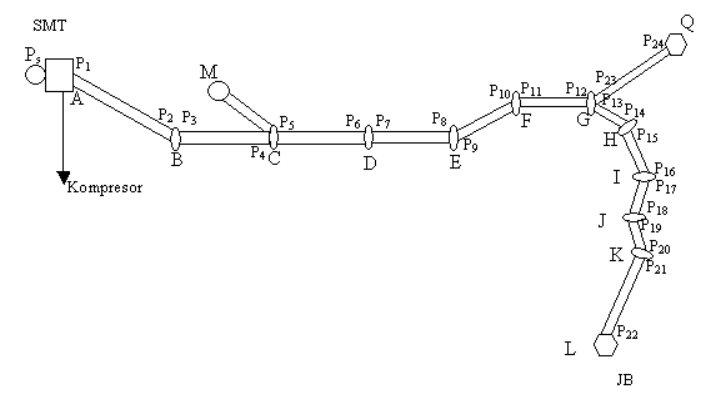

Gambar 1. Skema Jaringan Pipa dari A ke L

Konsumen di L dan Q menentukan berapa laju alir gas dan tekanan yang diperlukan oleh mereka. Perusahaan gas harus mendesain berapa diameter pipa yang dibutuhkan dan bagaimana distribusi tekanan harus diberikan agar gas dapat sampai ke L dan Q dengan laju alir dan tekanan yang diinginkan. Tekanan dari gas yang mengalir akan mengalami penurunanan sepanjang perjalanan. Hal ini harus diantisipasi oleh perusahaan gas, karena jika gas tersebut sampai ke konsumen dengan tekanan yang lebih rendah dari yang disepakati maka perusahaan akan terkena denda. Oleh kerena itu diperlukan kompresor untuk menaikan tekanan. Sebenarnya gas yang sudah mengalami proses pengolahan mempunyai tekanan tertentu. Hanya saja yang menjadi masalah adalah dengan tekanan tersebut apakah gas dapat mengalir dan sampai ke konsumen? Jika gas dapat sampai ke konsumen sesuai dengan permintaan, maka tidak diperlukan kompresor. Tapi apakah biaya minimum? Hal lain yang harus 
diperhatikan adalah pipa gas mempunyai keterbatasan dalam menahan tekanan, jadi perusahaan gas tidak dapat secara bebas memberikan tekanan yang tinggi dalam pengiriman gas.

Berkenan dengan pembahasan di atas maka, subbab berikut ini akan dibahas model dari alir gas dan model biaya yang dijadikan acuan untuk meminimumkan biaya pembangunan dan pengoperasian jaringan pipa transmisi gas.

Dalam menurunkan model laju alir gas dan biaya perlu diasumsikan beberapa hal untuk menyederhanakan permasalahan. Berdasarkan [3], asumsi yang dipakai adalah sebagai berikut :

1. Pipa lurus dan horisontal

2. Aliran gas dalam pipa steady-state

3. Temperatur gas sepanjang satu segmen pipa konstan

4. Tidak ada perubahan temperatur setelah gas keluar dari pipa

5. Faktor kompressibilitas gas (Z) sepanjang satu pipa konstan

6. Tidak ada faktor perubahan faktor kompressibilitas gas setelah keluar dari kompresor

7. Persamaan alir gas yang dipakai adalah persamaan Panhandle A dan persamaan Panhandle B.

8. Jenis kompresor yang dipakai adalah sentrifugal dan dipasang dititik awal.

9. Zat yang mengalir terdiri dari satu fasa atau gas saja

10. Perhitungan pajak, asuransi, biaya penambangan, dan faktor ekonomi lainnya diabaikan.

Berdasarkan asumsi diatas, sekarang akan ditentukan model laju alir gas dan biaya.

\section{Model Laju Alir Steady Gas Pipa Tunggal}

Persamaan dasar aliran gas diturunkan dari persamaan kesetimbangan energi dengan memasukkan persamaan empiris untuk harga faktor gesekan yang ada dalam persamaan tersebut, dan di asumsikan dalam keadaan tunak (steady). Berdasarkan [7] model laju alir gas pipa tunggal dengan faktor gesekan panhadle A adalah

$$
\begin{aligned}
& Q=0.000435\left(\frac{T_{b}}{P_{b}}\right)^{1.07881}\left(\frac{P_{1}^{2}-P_{2}^{2}}{T \operatorname{LmZ}}\right)^{0.53966} A_{1} \\
& A_{1}=\left(\frac{1}{S G g}\right)^{0.46033} d^{2.618996}\left(\frac{1}{\mu}\right)^{0.076331}
\end{aligned}
$$

Sedangan dengan faktor gesekan dengan model Panhandle B, persamaan laju alir gas adalah:

$$
\begin{aligned}
& Q=0.000737\left(\frac{T_{b}}{P_{b}}\right)^{1.02}\left(\frac{P_{1}^{2}-P_{2}^{2}}{T L m Z}\right)^{0.50999} A_{2} \\
& A_{2}=\left(\frac{1}{S G g}\right)^{0.49} d^{2.52998776}\left(\frac{1}{\mu}\right)^{0.01999}
\end{aligned}
$$

\footnotetext{
$Q \quad$ : laju alir gas (MMSCFD)

Lm : panjang pipa (ft)

SGg : gravitasi gas standar (standard gravity of
}

gas)

Z : faktor kompresibilitas gas

$T \quad$ : temperatur gas (Renkin)

$T_{b} \quad$ : temperatur dasar (Renkin)

$P_{b} \quad$ : tekanan dasar (psia)

$d \quad$ : diameter (inch)

$P_{1} \quad$ : adalah tekanan gas yang masuk ke dalam pipa (tekanan inlet), dan

$P_{2} \quad$ : adalah tekanan gas yang keluar dari pipa (tekanan outlet).

: viskositas gas (centipoise,cp).

Persamaan viskositas diperoleh dari korelasi LeeGonzales seperti yang tedapat pada [1] adalah

$\mu=0.0001 \frac{(9.4+0.02 M) T^{1.5} A_{3}}{209+19 M+T}$

$\left.\left.A_{3}=e^{\left(\left(3.5+\frac{986}{T}+0.01 M\right.\right.}\right)\left(0.043248 \frac{S G g\left(\frac{P_{1}+P_{2}}{2}\right)}{Z T}\right)\right)^{\left(1.7-\frac{197.2}{T}-0.02 M\right)}$

dengan $M$ adalah berat molekul, dan $M=28.97 S G g$

\section{Model Biaya Tahunan Pipa Tunggal}

Seperti telah disebutkan bahwa pengiriman gas bumi merupakan suatu proyek yang membutuhkan biaya sangat besar. Biaya tersebut meliputi biaya investasi dan biaya operasi.

Berdasarkan pada [3] model biaya tahunan untuk pipa tunggal adalah sebagai berikut:

Model biaya tahunan untuk satu segmen pipa berdasarkan [3] adalah sebagai berikut:

$$
C_{\text {total }}=\beta C I C+C I P+\beta . O C k o m p+O C p i p a
$$

dengan

$\beta= \begin{cases}1 & \text { jika kompresor dipasang } \\ 0 & \text { jika kompresor tidak dipasang }\end{cases}$

$$
\begin{aligned}
& C I P=\frac{r(1+r)^{n}(1+R p) C p L^{l} d^{m}}{(1+r)^{n}-1} \\
& C I C=\frac{r(1+r)^{n}}{(1+r)^{n}-1} \text { Ckomp } \\
& \text { OCkomp }=(1+\text { Copkomp }) \cdot C_{\text {Listrik }}
\end{aligned}
$$

$$
\text { OCpipa }=\frac{r(1+r)^{n}(1+R p) C f p C p L^{l} d^{m}}{(1+r)^{n}-1}
$$

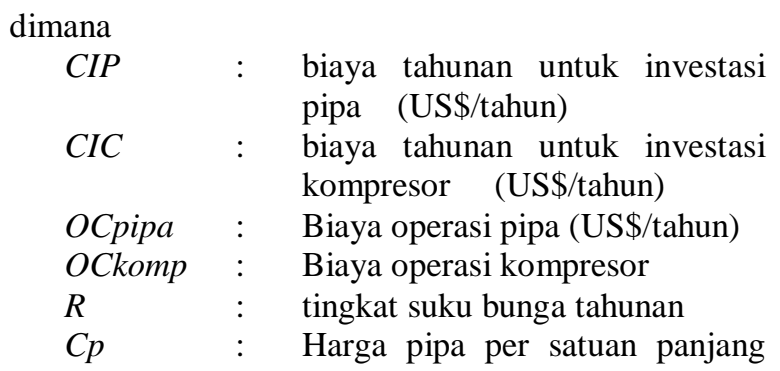




\begin{tabular}{|c|c|c|}
\hline & & dan diameter (US\$/ft.inch) \\
\hline$R p$ & : & $\begin{array}{l}\text { Fraksi antara biaya pemasangan } \\
\text { dengan harga pipa }\end{array}$ \\
\hline$L$ & & panjang pipa (feet) \\
\hline 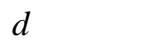 & : & diameter pipa(inch) \\
\hline$C f p$ & : & $\begin{array}{l}\text { Fraksi antara biaya tahunan } \\
\text { investasi pipa dan operasi pipa }\end{array}$ \\
\hline Copkomp & : & $\begin{array}{l}\text { Fraksi biaya operasi lain selain } \\
\text { listrik dengan biaya listrik } \\
\text { kompresor }\end{array}$ \\
\hline l & & $\begin{array}{l}\text { konstanta ketaklinieran antara } \\
\text { harga pipa dan panjang pipa }\end{array}$ \\
\hline$n$ & : & $\begin{array}{l}\text { konstanta ketaklinieran antara } \\
\text { harga pipa dan diameter pipa }\end{array}$ \\
\hline$C_{\text {Listrik }}$ & & $\begin{array}{l}\text { Biaya listrik yang digunakan } \\
\text { untuk operasikan kompresor }\end{array}$ \\
\hline
\end{tabular}

Perlu diketahui pula bahwa $l$ dan $m$ dapat ditentukan dengan regresi linier jika kita mempunyai data harga pipa.

$$
\text { Ckomp }=\text { Chp }(g p h)^{b}
$$

dengan

$$
\begin{array}{ll}
\text { Chp } & \text { : harga kompresor (US\$/hp) } \\
\text { gph } & : \text { daya kompresor sentrifugal } \\
b & : \text { konstanta ketaklinieran harga kompresor } \\
& \text { terhadap daya kompresor }
\end{array}
$$

$$
g p h=\frac{3125}{2061} \frac{Q P_{b} T_{1}\left(Z_{1}+Z_{2}\right)\left[\left(\frac{P_{2}}{P_{1}}\right)^{\left(\frac{k-1}{k E p}\right)}-1\right] k}{T_{b}(k-1)}+b l+s l
$$

dimana

$$
\begin{aligned}
& Z_{1} \quad \text { : faktor kompressibilitas gas } \\
& Z_{2} \quad \text { : faktor kompressibilitas gas } \\
& P_{1} \quad: \quad \text { tekanan gas sebelum melalui } \\
& P_{2} \quad \text { : tekanan gas sesudah melalui } \\
& \text { Ep : } \quad \begin{array}{l}
\text { kompresor } \\
\text { eksponen adiabatik }
\end{array} \\
& k \quad: \quad \text { efisiensi kompresor }
\end{aligned}
$$

$$
\begin{aligned}
& C_{\text {Listrik }}=\frac{1}{8760}\left(19809.32047 A_{4}+6532.321518(b l+s l) C e H y\right. \\
& A_{4}=\frac{Q P_{b} T Z\left[\left(\frac{P_{2}}{P_{1}}\right)^{\left(\frac{k-1}{k E p}\right)}-1\right] k}{T_{b}(k-1)}
\end{aligned}
$$

dengan

Ce : biaya listrik

Hy : jam operasi pertahun

\section{Model Biaya dan Laju Alir untuk N Segmen Pipa}

Model biaya tahunan untuk $\mathrm{N}$ segmen pipa adalah sebagai berikut:

$$
\begin{gathered}
C_{\text {total }}=\beta \frac{r(1+r)^{n}}{(1+r)^{n}-1} \text { Ckomp }+\beta . \text { OCkomp }+ \text { CIP }_{i}+\text { OCpipa }_{i} \\
\text { CIP } P_{i}=\sum_{i=1}^{N} \frac{r(1+r)^{n}(1+R p) C p L_{i}^{l} d_{i}^{m}}{(1+r)^{n}-1} \\
\text { OCpipa }_{i}=\sum_{i=1}^{N} \frac{r(1+r)^{n}(1+R p) C f p C p L_{i}^{l} d_{i}^{m}}{(1+r)^{n}-1}
\end{gathered}
$$

Berdasarkan persamaan Panhandle A, laju alir gas untuk $\mathrm{N}$ segmen pipa adalah dengan mensubstitusikan nilai $P$ dan $\Delta P$ ke persamaan diatas, diperoleh persamaan laju alir gas untuk model Penhandle A sebagai berikut:

$$
\begin{aligned}
& Q_{i}=0.000435\left(\frac{T_{b}}{P_{b}}\right)^{1.07881}\left(\frac{P_{i+1}^{2}-P_{i+2}^{2}}{T_{i} L m_{i} Z}\right)^{0.53966} A_{1 i} \\
& A_{1 i}=\left(\frac{1}{S G g_{i}}\right)^{0.46033} d_{i}^{2.618996}\left(\frac{1}{\mu_{i}}\right)^{0.076331}
\end{aligned}
$$

sedangkan berdasarkan persamaan Penhandle B diperoleh

$$
\begin{aligned}
& Q_{i}=0.000737\left(\frac{T_{b}}{P_{b}}\right)^{1.02}\left(\frac{P_{i+1}^{2}-P_{i+2}^{2}}{T_{i} L m_{i} Z}\right)^{0.50999} A_{2 i} \\
& A_{2 i}=\left(\frac{1}{S G g_{i}}\right)^{0.49} d_{i}^{2.52998776}\left(\frac{1}{\mu_{i}}\right)^{0.01999}
\end{aligned}
$$

dengan

$$
\mu_{i}=0.0001 \frac{\left(9.4+0.02 M_{i}\right) T_{i}^{1.5} A_{3 i}}{209+19 M_{i}+T_{i}}
$$

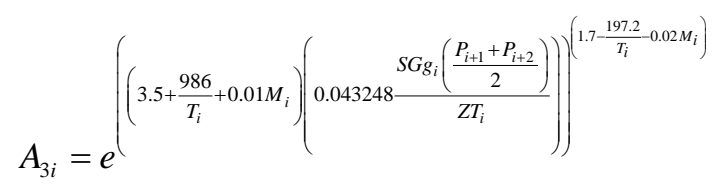

dimana $M_{i}=28.97 S G g_{i}, \quad i=1,2,3, \ldots N$

\section{Tarif Toll Transportasi (Tollfee)}

Tollfee adalah biaya yang harus dibayar pemakai jaringan pipa transmisi untuk setiap volume gas yang dialirkan melalui sistem pemipaan tersebut. Tollfee ditetapkan berdasarkan laju pengembalian investasi yang dipengaruhi oleh berbagai batasan.

Perhitungan Tollfee sebenarnya melibatkan banyak faktor ekonomi, tetapi dalam tulisan ini dibahas metode perhitungan Tollfee yang sederhana. Sesuai dengan asumsi kita bahwa perhitungan pajak dapat diabaikan, maka Tollfee dapat dihitung sebagai berikut:

1. Hitung biaya tahunan pembangunan dan pengoperasian sistem jaringan pipa (tanpa biaya penambangan). Dalam hal ini kita sebut biaya tahunan sebagai $C_{\text {total }}$

2. $C_{\text {total }}$ dapat dipisah menjadi CIP, CIC, OCpipa, dan OCkomp.

3. CIP dan OCpipa dipisah setiap segmen diperoleh $C I P=C I P_{1}+C I P_{2}+C I P_{3}+\ldots+C I P_{N}$ OCpipa $=$ OCpipa $_{1}+$ OCpipa $_{2}+\ldots+$ OCpipa $_{N}$

4. Berdasarkan asumsi bahwa kompresor terletak pada awal segmen, maka kompresor tersebut akan 
mempengaruhi gas yang mengalir pada semua segmen, dengan demikian CIC dan OCkomp dibagi ke tiap segmen dengan melakukan pembobotan berdasarkan panjang pipa.

$$
\begin{aligned}
\text { CIC }_{i} & =\frac{L_{i}}{L_{f}} \text { CIC } \\
\text { OCkomp }_{i} & =\frac{L_{i}}{L f} \text { OCkomp }
\end{aligned}
$$

dengan $L f$ adalah panjang total pipa.

5. Besar Tollfee tiap segmen berdasarkan [6] adalah

$$
T f_{i}=\frac{C I P i+\text { OCpipa }_{i}+\text { CIC }_{i}+\text { OCkomp }_{i}}{Q_{i}(365)(1000)}
$$

\section{Metode Optimisasi}

Berdasarkan penjelasan sebelumnya persamaan (11) dapat dipandang sebagai fungsi objektif biaya, sedangkan persamaan (12) dan persamaan (13) masing-masing merupakan fungsi kendala panhandle A dan penhandle B. Dengan demikian permasalahan kita adalah meminimumkan fungsi objektif biaya terhadap fungsi biaya. Dalam bagian ini dibahas metode yang digunakan untuk proses optimisasi dimaksud.

\section{Penurunan Metode Optimasi}

Berdasarkan [2], misalkan kita mempunyai fungsi objektif $C(x)$ dengan fungsi kendala $W_{i}(x)$, untuk $i$ $=1,2, \ldots, M$. Nilai minimum dari fungsi $C(x)$ yang memenuhi $W_{i}(x)=0$ dicapai pada titik $U(T)=x^{*}$; yaitu suatu titik yang diperoleh ketika kurva ketinggian fungsi $C(x)$ bersinggungan dengan fungsi kendala $W i(x)=0$. Untuk memperoleh titik tersebut kita memulai proses pengotimasian dari titik $U(0)=x 0$; yaitu suatu titik yang juga memenuhi kendala $W i(x)=0$.

Untuk sampai pada titik $U(T)=x^{*}$ kita setiap langkah kita haruslah memenuhi $W i(x)=0$, dengan kata lain setiap titik yang diperoleh harus memenuhi $W_{i}(x)=0$ : Untuk mencapai kondisi ini setiap arah gerak harus menyinggung $W_{i}(x)=0$. Arah gerak ini yang kita sebut $U t$ yang berbentuk:

$$
U t=-\nabla C(x)+\sum_{j=1}^{M} \alpha_{j} \nabla W_{j}(x)
$$

dengan $\alpha_{j}$ adalah suatu nilai tertentu dan $t$ adalah parameter iterasi.

Ut juga merupakan kombinasi linier dari $\nabla C(x)$ dan $\nabla W_{i}(x), i=1,2, \ldots, M$. Agar selalu menyinggung fungsi kendala $W_{i}(x)=0$, haruslah pada $W_{i}(x)=0$ berlaku:

$$
\begin{aligned}
\frac{d W_{i}}{d t} & =\nabla W_{i} \circ U t=0 \\
& =\nabla W_{i}(x) \circ\left(-\nabla C(x)+\sum_{j=1}^{M} \alpha_{j} \nabla W_{j}(x)\right) \\
& =-\nabla W_{i}(x) \circ \nabla C(x)+\sum_{j=1}^{M} \alpha_{j} \nabla W_{i}(x) \circ \nabla W_{j}(x)=0
\end{aligned}
$$

sehingga

$$
\sum_{j=1}^{M} \alpha_{j} \nabla W_{i}(x) \circ \nabla W_{j}(x)=\nabla W_{i}(x) \circ \nabla C(x)
$$

Dengan demikian $\alpha_{j}$ dapat ditentukan sebagai berikut

$$
A \alpha=B
$$

dimana

$$
\begin{aligned}
& A=\left[\begin{array}{cccc}
\nabla W_{1} \circ \nabla W_{1} & \nabla W_{1} \circ \nabla W_{2} & \cdots & \nabla W_{1} \circ \nabla W_{N} \\
\nabla W_{2} \circ \nabla W_{1} & \nabla W_{2} \circ \nabla W_{2} & \cdots & \nabla W_{2} \circ \nabla W_{N} \\
\vdots & \ldots & \ddots & \vdots \\
\nabla W_{N} \circ \nabla W_{1} & \nabla W_{N} \circ W_{2} & \ldots & \nabla W_{N} \circ \nabla W_{N}
\end{array}\right] \\
& \alpha=\left[\begin{array}{c}
\alpha_{1} \\
\alpha_{2} \\
\vdots \\
\alpha_{N}
\end{array}\right] \quad B=\left[\begin{array}{l}
\nabla W_{1} \circ \nabla C \\
\nabla W_{2} \circ \nabla C \\
\vdots \\
\nabla W_{N} \circ \nabla C
\end{array}\right]
\end{aligned}
$$

Dan dapat ditulis sebagai

$$
\alpha=A^{-1} B
$$

\section{Metode Rangekutta Orde 4}

Pandang Ut sebagai persamaan diferensial orde satu yang diketahui nilai awal $U(0)=x_{0}$ : Dengan demikian kita mempunyai MNA yang berbentuk:

$$
U(0)=x_{0}, \quad U t=-\nabla C\left(x_{k}\right)+\sum_{j=1}^{M} \alpha_{j} \nabla W_{j}\left(x_{k}\right)
$$

Dengan pendekatan numerik permasalahan diatas dapata diselesaikan dengan metode Rangekutta orde 4.

Dalam proses penyelesaiannya, metode ini digunakan untuk menghitung hampiran solusi pada titik-titik $x=$ $x_{1}, x_{2, \ldots}$ dengan $x_{i}=x_{0}+i h$ dan $h$ menyatakan ukuran langkah. Menurut [5], skema untuk menghampiri fungsi $U$ pada $x_{1}=x_{0}+h$ adalah sebagai berikut:

dengan

$$
U\left(x_{1}\right)=U\left(x_{0}\right)+\left(k_{1}+2 k_{2}+2 k_{3}+k_{4}\right) / 6
$$

$$
\begin{aligned}
& k_{1}=h f\left(x_{0}\right) \\
& k_{2}=h f\left(x_{0}+k_{1} / 2\right) \\
& k_{3}=h f\left(x_{0}+k_{2} / 2\right) \\
& k_{4}=h f\left(x_{0}+k_{3}\right)
\end{aligned}
$$

dimana

$$
f\left(x_{k}\right)=-\nabla C\left(x_{k}\right)+\sum_{j=1}^{M} \alpha_{j} \nabla W_{j}\left(x_{k}\right)
$$

Secara iteratif fungsi $U$ dapat dihitung dititik $x_{2}, x_{3}, \ldots$

\section{HASIL DAN PEMBAHASAN}

\section{Implementasi dan Analisis Hasil Optimisasi}

Model laju alir dan biaya, serta metode optimisasi yang diperoleh dari bagian sebelumnya akan diimplementasikan dalam suatu jaringan pipa transmisi gas dengan percabangan (lihat Gambar 1.) Dalam jaringan ini pada daerah $\mathrm{C}$ terdapat penambahan laju alir, akibat dari adanya tambahan gas yang bersumber di M. Dengan mengasumsikan bahwa segmen pipa dari $\mathrm{M}$ ke $\mathrm{C}$ tidak 
diperhitungkan dalam proses optimisasi, secara keseluruhan terdapat 12 segmen pipa.

Dengan meredenifinisikan beberapa variabel, model biaya tahunan dan model laju alir diperoleh dari bagian kedua. Kita mendefinisikan fungsi objektif biaya sebagai berikut:

$$
\begin{gathered}
C_{\text {total }}=\beta C I C+C I P_{i}+\beta . \text { OCkomp }+ \text { OCpipa }_{i} \\
C I P_{i}=\sum_{i=1}^{12} \frac{r(1+r)^{n}(1+R p) C p L_{i}^{l} d_{i}^{m}}{(1+r)^{n}-1} \\
\text { OCpipa }_{i}=\sum_{i=1}^{12} \frac{r(1+r)^{n}(1+R p) C f p C p L_{i}^{l} d_{i}^{m}}{(1+r)^{n}-1} \\
Q_{i}=0.000435\left(\frac{T_{b}}{P_{b}}\right)^{1.07881}\left(\frac{P_{2 i-1}^{2}-P_{2 i}^{2}}{T_{i} L m_{i} Z}\right)^{0.53966} A_{1 i}=0 \\
A_{1 i}=\left(\frac{1}{S G g_{i}}\right)^{0.46033} d_{i}^{2.618996}\left(\frac{1}{\mu_{i}}\right)^{0.076331}
\end{gathered}
$$

sedangkan berdasarkan persamaan Penhandle B diperoleh

$$
\begin{aligned}
& Q_{i}=0.000737\left(\frac{T_{b}}{P_{b}}\right)^{1.02}\left(\frac{P_{2 i-1}^{2}-P_{2 i}^{2}}{T_{i} L m_{i} Z}\right)^{0.50999} A_{2 i}=0 \\
& A_{2 i}=\left(\frac{1}{S G g_{i}}\right)^{0.49} d_{i}^{2.52998776}\left(\frac{1}{\mu_{i}}\right)^{0.01999}
\end{aligned}
$$

\begin{tabular}{|c|c|c|c|}
\hline Simbol & Keterangan & Nilai & Satuan \\
\hline $\bar{Z}$ & faktor kompressibilitas gas & 0.9 & \\
\hline$T$ & Temperatur pipa & 5500 & Renkin \\
\hline$S G g$ & gravitasi gas standar & 0.624 & \\
\hline $\mathrm{Pb}$ & Tekanan Dasar & 14.73 & psia \\
\hline$T b$ & Temperatur Dasar & 5200 & Renkin \\
\hline$P s$ & Tek. Gas sblm masuk & 1000 & psia \\
\hline$B l$ & kompresor bearing losses & 30 & \\
\hline Sl & seal losses & 20 & \\
\hline$R p$ & $\begin{array}{l}\text { fraksi biaya pemasangan } \\
\text { dengan harga pipa }\end{array}$ & 1.4 & \\
\hline$E p$ & ekponen adiabatik & 0.9 & \\
\hline$K$ & efisiensi kompresor & 1.24 & \\
\hline$C f p$ & $\begin{array}{llr}\text { fraksi } & \text { biaya } & \text { tahunan } \\
\text { investasi } & \text { dengan } & \text { operasi } \\
\text { pipa } & & \\
\end{array}$ & 0.2 & \\
\hline$C p$ & harga pipa & $\begin{array}{l}0.5698 \\
48\end{array}$ & $\begin{array}{l}\text { US\$/ft.in } \\
\text { ch }\end{array}$ \\
\hline Chp & harga kompresor & 1500 & US\$/hp \\
\hline$L$ & $\begin{array}{l}\text { konstanta ketaklinieran } \\
\text { harga dengan panjang pipa }\end{array}$ & 1 & \\
\hline$M$ & $\begin{array}{l}\text { konstanta ketaklinieran } \\
\text { harga dengan diameter pipa }\end{array}$ & $\begin{array}{l}1.4281 \\
78\end{array}$ & \\
\hline$N$ & jangka waktu pembayaran & 20 & \\
\hline$R$ & tingkat suku bunga tahunan & 0.12 & \\
\hline $\mathrm{Ce}$ & biaya listrik & 0.055 & \\
\hline Hy & jam operasi pertahun & 8760 & \\
\hline $\begin{array}{l}\text { Copkom } \\
p\end{array}$ & $\begin{array}{l}\text { fraksi biaya operasi selain } \\
\text { listrik dengan biaya listrik } \\
\text { kompresor }\end{array}$ & 0.75 & \\
\hline$B$ & $\begin{array}{l}\text { konstanta ketaklinieran } \\
\text { harga terhadap daya } \\
\text { kompresor }\end{array}$ & 1 & \\
\hline
\end{tabular}

dengan $i=1,2,3, \ldots, 12$

\section{Asumsi Data}

Data masukan yang dipakai dalam proses optimisasi ini adalah sebagai berikut :

Tabel 1. Data masukan yang berupa tetapan
Sedangkan data dari jaringan pipa transmisi SMTJB adalah sebagai berikut:

Tabel 2. Data yang ada di lapangan

\begin{tabular}{|c|c|c|}
\hline Segmen & Daerah & Panjang $(\mathrm{Km})$ \\
\hline 1 & A-B & 39 \\
\hline 2 & B-C & 23 \\
\hline 3 & C-D & 19 \\
\hline 4 & D-E & 17.15 \\
\hline 5 & E-F & 13.2 \\
\hline 6 & F-G & 10 \\
\hline 7 & G-H & 11.5 \\
\hline 8 & H-I & 7.9 \\
\hline 9 & I-J & 10.5 \\
\hline 10 & J-K & 13.2 \\
\hline 11 & K-L & 19.2 \\
\hline 12 & G-Q & 10.1 \\
\hline
\end{tabular}

Dengan menggunakan asumsi data yang ada dan dengan menganggap temperatur pipa pada setiap segmen sama, maka terdapat 39 variabel optimasi yaitu $\left\{d_{1}, \ldots\right.$, $\left.d_{11}, P_{1}, \ldots, P_{24}\right\}$ dengan $P_{1}$ adalah tekanan inlet setelah melewati kompresor dianggap sebagai tekanan di A, $P_{22}$ sebagai tekanan outlet di L serta $P_{24}$ adalah tekanan outlet di N .

\section{Kondisi Awal}

Dalam memilih kondisi awal $U(0)=x_{0}=\left(d_{1}{ }^{0}, \ldots, d_{11}{ }^{0}\right.$, $\left.P_{1}{ }^{0}, \ldots, P_{24}{ }^{0}\right)$ haruslah memenuhi kendala $P A_{i}=0$, dimana $i=1,2, \ldots, 12$. Dan untuk menghindari perhitungan imaginer $P_{2 i-1}^{0}>P_{2 i}^{0}$. Untuk memudahkan kita diberikan suatu metode khusus, yakni:

\subsection{Metode Penarik}

Dalam proses optimisasi menentukan kondisi awal $x_{0}$ sangat penting karena harus memenuhi persamaan kendala $P A_{j}\left(x_{0}\right)=0$. Oleh karena itu diperlukian kiat khusus agar kondisi awal kita tidak perlu memenuhi persamaan kendala $P A_{j}\left(x_{0}\right)=0$, dengan menarik nilai awal tersebut ke kendala. Metode penarik berbentuk:

$$
x_{k+1}=x_{k}-h_{k} \sum_{j=1}^{M} P A_{j} \nabla P A_{j}\left(x_{k}\right)
$$

\subsection{Kendala Tambahan}

Telah diketahui bahwa kendala yang digunakan dalam model ini adalah Persamaan laju alir gas yang diturunkan berdasarkan persamaan panhandle A dan penhandle B. Namun karena tekanan inlet dan tekanan oulet ditetapkan maka ini dapat dijadikan sebagai kendala. Pada titik percabangan dimana terjadi penambahan laju alir, tekanan pada titik tersebut tidak terjadi perubahan, dalam hal laju alir mengalami penurunan tekanan yang keluar dari titik percabangan itu dianggap sama, sedangkan untuk titik pertemuan antar segmen tanpa percabangan tekanannya sama. Perlu diketahui pula dalam proses optimisasi tekanan yang diperoleh tidak boleh lebih besar dari tekanan maksimum pipa. Dengan demikian tekanan maksimum dalam pipa juga merupakan kendala. Dalam hal ini proses optimisasi akan berhenti jika tekanan telah melebihi tekanan maksimum pipa. 


\section{Hasil Optimisasi dan Analisis}

Hasil optimisasi disini dibagi dalam dua kasus yakni yang pertama pada cabang keluaran yaitu dititik G, laju alir gas yang keluar dari titik tersebut dibuat sama, sedangkan untuk kasus yang kedua dibuat tidak sama yaitu pada segmen 7 laju alirnya lebih besar dari segmen 12. Dalam kedua kasus ini tekanan di titik percabangan di anggap sama.

\subsection{Kasus 1}

Dalam kasus ini optimisasi menggunakan flowrate pada segmen 1 dan segmen 2, 1000 mmscfd, untuk segmen 3 sampai segmen 6, 1250 mmscfd, untuk segmen 7 sampai segmen 11, 625 mmscfd, dan segmen 1, 625 mmscfd. Selanjutnya $\mathrm{P}_{1}=1500$ psia; $\mathrm{P}_{22}=500$ psia; dan $\mathrm{P}_{24}=400$ psia: Hasil optimisasinya dapat dilihat dalam Tabel 3 dan Tabel 4.

Tabel 3. Hasil Optimisasi Kasus 1, dengan kendala persamaan panhandle A

\begin{tabular}{|c|c|c|c|c|c|}
\hline Seg & Diameter & $\mathrm{P}$ inlet & $\mathrm{P}$ outlet & Biaya (\$/ft.thn) & Tollfee \\
\hline 1 & 24.287 & 1500.000 & 1346.690 & \multirow{12}{*}{47.283} & 0.0170 \\
\hline 2 & 24.287 & 1346.690 & 1248.041 & & 0.0100 \\
\hline 3 & 25.940 & 1248.041 & 1151.643 & & 0.0069 \\
\hline 4 & 25.940 & 1151.643 & 1057.515 & & 0.0062 \\
\hline 5 & 25.940 & 1057.515 & 979.227 & & 0.0048 \\
\hline 6 & 25.940 & 979.227 & 915.675 & & 0.0036 \\
\hline 7 & 20.889 & 915.675 & 853.871 & & 0.0074 \\
\hline 8 & 20.889 & 853.871 & 808.790 & & 0.0051 \\
\hline 9 & 20.889 & 808.790 & 744.817 & & 0.0067 \\
\hline 10 & 20.889 & 744.817 & 655.909 & & 0.0084 \\
\hline 11 & 20.888 & 655.909 & 500.000 & & 0.0123 \\
\hline 12 & 13.934 & 915.675 & 400.000 & & 0.0054 \\
\hline & & & & Total Tollfee & 0.0939 \\
\hline
\end{tabular}

Tabel 4. Hasil Optimisasi Kasus 1, dengan kendala persamaan panhandle B

\begin{tabular}{|c|c|c|c|c|c|}
\hline Seg & Diameter & P inlet & $\mathrm{P}$ outlet & Biaya $(\$ / \mathrm{ft}$. thn $)$ & Tollfee \\
\hline 1 & 27.478 & 1500.000 & 1348.333 & \multirow{12}{*}{51.054} & 0.0184 \\
\hline 2 & 27.478 & 1348.333 & 1250.441 & & 0.0109 \\
\hline 3 & 29.426 & 1250.441 & 1154.172 & & 0.0075 \\
\hline 4 & 29.426 & 1154.172 & 1059.901 & & 0.0068 \\
\hline 5 & 29.426 & 1059.901 & 981.276 & & 0.0052 \\
\hline 6 & 29.426 & 981.276 & 917.290 & & 0.0040 \\
\hline 7 & 23.502 & 917.290 & 855.600 & & 0.0079 \\
\hline 8 & 23.502 & 855.600 & 810.535 & & 0.0054 \\
\hline 9 & 23.502 & 810.535 & 746.480 & & 0.0072 \\
\hline 10 & 23.502 & 746.480 & 657.238 & & 0.0090 \\
\hline 11 & 23.502 & 657.238 & 500.000 & & 0.013 \\
\hline 12 & 15.825 & 917.290 & 400.000 & & 0.0057 \\
\hline \multicolumn{5}{|r|}{ Total Tollfee } & 0.1011 \\
\hline
\end{tabular}

Dalam bentuk grafik distribusi tekanan dan diameter pada setiap segmen adalah sebagai berikut:

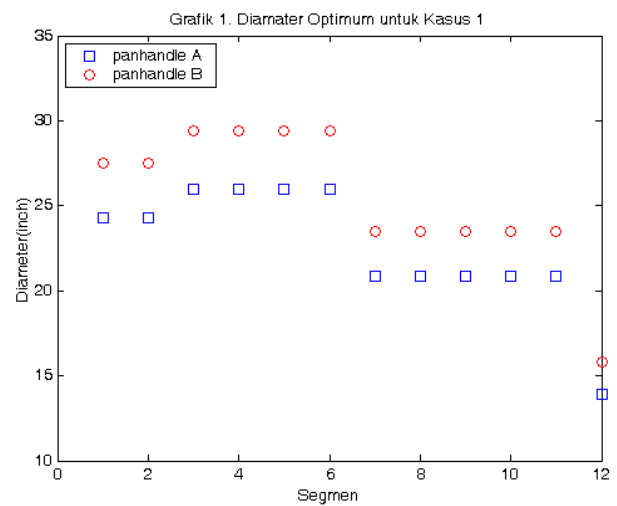

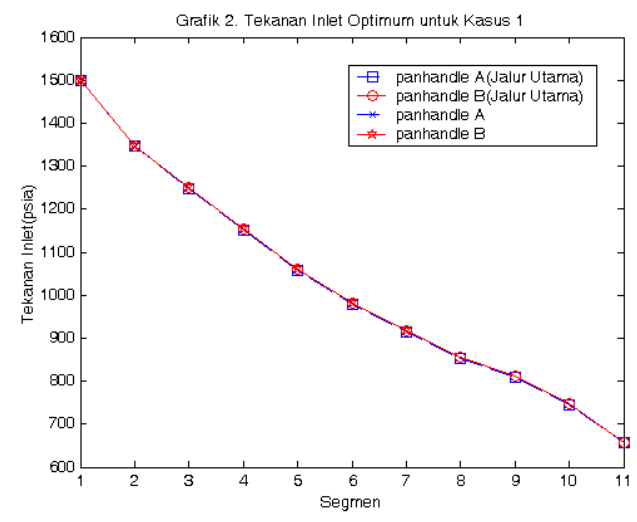

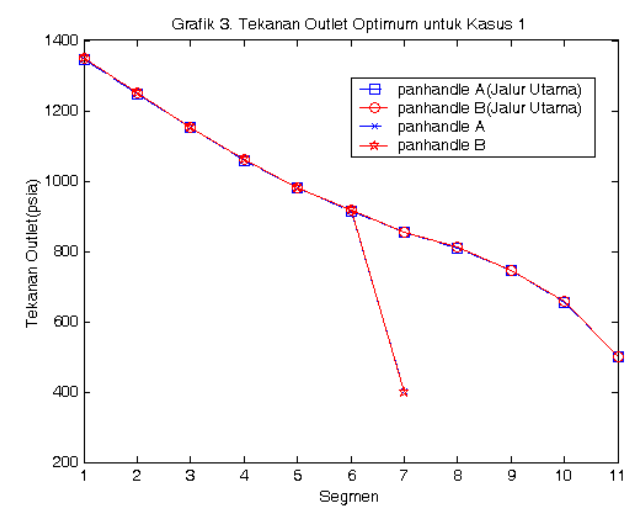

Dari hasil yang diperoleh dari tabel maupun dari grafik terlihat bahwa pada jalur utama besar diameter optimal bergantung pada laju alirnya. Jika segmen mempunyai laju alir yang sama maka diameter optimum dari segmen tersebut juga sama. Seperti dalam tabel maupun grafik untuk segmen 1 dan segmen 2, dimana laju alirnya sama yakni 1000 mmscfd, diameter optimumnya sama yaitu 24.287 inch untuk optimisasi dengan panhandle A dan 27.678 inch bila optimisasi dengan panhandle B. Untuk segmen 3 sampai segmen 6 dengan laju alir 1250 mmscfd juga mempunyai diameter optimum yang sama, demikian pula untuk segmen 7 sampai segmen 11 dengan laju alir 625 mmscfd. Namun pada segmen percabangan yakni segmen 12 walaupun laju alir di segmen tersebut sama dengan di segmen 7, terlihat bahwa diameter optimum cukup kecil hal ini karena panjang segmen tersebut pendek dan tekanan outputpnya ditetapkan kecil.

Untuk distribusi tekanan, terlihat bahwa tekanan terus turun di setiap segmen untuk jalur utama maupun percabangan. Dari Grafik 2. dan Grafik 3. tekanan inlet maupun tekanan outlet untuk setiap segmen tidak terdapat perbedaan yang signifikan bila optimasi dilakukan dengan kendala panhandle A dan panhandle B. Hal ini karena telah ditetapkan terlebih dahulu tekanan inlet dan tekanan outlet dari jaringan pipa.

\subsection{Kasus 2}

Optimisasi di sini menggunakan flowrate pada segmen ke 1 dan 2, 1000 mmscfd, untuk segmen 3 sampai segmen 6, 1250 mmscfd, untuk segmen 7 sampai segmen 11, 750 mmscfd, dan untuk segmen 12, 500 mmscfd. Selanjutnya $\mathrm{P} 1=1500$ psia; $\mathrm{P} 22=500$ psia; $\mathrm{dan}$ P24 = 
400 psia. Hasil dari optmisasi tersebut dapat dilihat dalam Tabel 5 dan Tabel 6.

Tabel 5. Hasil Optimisasi Kasus 2, dengan kendala persamaan panhandle A

\begin{tabular}{|c|c|c|c|c|c|}
\hline Seg & Diameter & $\mathrm{P}$ inlet & $\mathrm{P}$ outlet & Biaya $(\$ / \mathrm{ft}$. thn $)$ & Tollfee \\
\hline 1 & 24.388 & 1500.000 & 1349.908 & \multirow{12}{*}{47.790} & 0.0171 \\
\hline 2 & 24.388 & 1349.908 & 1253.532 & & 0.0101 \\
\hline 3 & 26.048 & 1253.532 & 1159.554 & & 0.0069 \\
\hline 4 & 26.048 & 1159.554 & 1068.030 & & 0.0063 \\
\hline 5 & 26.048 & 1068.030 & 992.138 & & 0.0048 \\
\hline 6 & 26.048 & 992.138 & 930.722 & & 0.0036 \\
\hline 7 & 22.185 & 930.722 & 866.999 & & 0.0063 \\
\hline 8 & 22.185 & 866.999 & 820.478 & & 0.0044 \\
\hline 9 & 22.185 & 820.478 & 754.384 & & 0.0058 \\
\hline 10 & 22.185 & 754.384 & 662.331 & & 0.0073 \\
\hline 11 & 22.185 & 662.331 & 500.000 & & 0.0106 \\
\hline 12 & 12.692 & 930.722 & 400.000 & & 0.0065 \\
\hline & & & & Total Tollfee & 0.0897 \\
\hline
\end{tabular}

Tabel 6. Hasil Optimisasi Kasus 2, dengan kendala persamaan panhandle B

\begin{tabular}{|c|c|c|c|c|c|}
\hline Seg & Diameter & $\mathrm{P}$ inlet & $\mathrm{P}$ outlet & Biaya (\$/ft.thn) & Tollfee \\
\hline 1 & 27.593 & 1500.000 & 1351.626 & \multirow{12}{*}{51.675} & 0.0185 \\
\hline 2 & 27.594 & 1351.626 & 1256.074 & & 0.0109 \\
\hline 3 & 29.549 & 1256.074 & 1162.317 & & 0.0076 \\
\hline 4 & 29.549 & 1162.317 & 1070.764 & & 0.0068 \\
\hline 5 & 29.549 & 1070.764 & 994.651 & & 0.0053 \\
\hline 6 & 29.549 & 994.651 & 932.916 & & 0.0040 \\
\hline 7 & 25.017 & 932.916 & 869.258 & & 0.0068 \\
\hline 8 & 25.017 & 869.258 & 822.709 & & 0.0047 \\
\hline 9 & 25.017 & 822.709 & 756.464 & & 0.0062 \\
\hline 10 & 25.017 & 756.464 & 663.961 & & 0.0078 \\
\hline 11 & 25.017 & 663.961 & 500.000 & & 0.0114 \\
\hline 12 & 14.369 & 932.916 & 400.000 & & 0.0068 \\
\hline & & & & Total Tollfee & 0.0967 \\
\hline
\end{tabular}

Dalam bentuk grafik distribusi tekanan dan diameter pada setiap segmen dalam kasus ini adalah sebagai berikut:




Dari hasil yang ditampilkan dalam tabel dan grafik dalam kasus di sini, sama halnya dengan kasus sebelumnya terlihat bahwa optimisasi dengan menggunakan kendala, panhadle A lebih baik dari hasil optimisasi dengan menggunakan kendala panhandle B masih tetap lebih baik. Dalam tabel terlihat bahwa pada jalur utama pun, diameter pipa akan sama, jika laju alir dalam pipa tersebut sama.

Dalam kasus ini telihat bahwa bila segmen 12 dikurangi laju alirnya dan segmen 7 sampai segmen11 ditambah laju alirnya maka, diameter optimum di segmen 12 akan mengecil sedangkan diameter optimum di segmen 7 sampai 11 akan membesar. Sedangkan untuk jalur lainnya tidak terjadi perubahan yang signifikan. Sama halnya dengan kasus sebelumnya dari grafik 5, dan grafik 6 , terlihat bahwa tekanan inlet maupun tekanan outlet dari setiap segmen cenderung sama, baik untuk optimisasi dengan kendala panhandle A maupun panhandle $\mathrm{B}$.

\section{KESIMPULAN DAN SARAN}

\section{Kesimpulan}

Berdasarkan hasil pembahasan dari bab-bab sebelumnya dapat disimpulkan bahwa

1. Diameter pipa optimum untuk optimisasi dengan kendala panhandle A lebih kecil dibandengkan dengan bila optimisasi dengan kendala panhandle B.

2. Titik percabangan berpengaruh dalam proses optimisasi ini. Karena pada titik percabangan tersebut terjadi panambahan maupun pengurangan laju alir

3. Dengan laju alir yang sama diameter pipa belum tentu sama hal ini karena pengaruh tekanan dan panjang pipa.

4. Distribusi tekanan inlet maupun tekanan outlet dalam setiap segmen pipa sama, untuk optimisasi dengan kendala panhandle A maupun panhandle

5. Akibat dari 1 dan 4 maka optimisasi dengan kendala panhandle A menghasilkan biaya yang lebih kecil dari optimisasi dengan kendala panhandle B.

\section{Saran}

1. Hasil yang ditampilkan dalam tulisan ini hanya terdiri dari dua kasus saja. Sebenarnya masih dapat dikembangkan ke bebagai kasus dengan variasi laju alir, tekanan inlet, dan tekanan outlet hanya saja 
dibutuhkan cukup lama waktu untuk proses optimisasi. Dengan demikian diharapkan akan dilakukan proses optimisasi dengan berbagai variasi tersebut dikemudian hari.

2. Dalam melakukan proses optimisasi dengan menggunakan MATLAB dibutuhkan cukup lama waktu agar hasil dapat ditampilkan, hal ini mungkin karena keterbatasan dari penulis ataupun mungkin karena keterbatasan dari MATLAB, oleh karena itu disarankan agar proses optimisasi ini dapat dikerjakan dengan program lain dikemudian hari.

3. Tampilan program untuk permasalahan ini juga belumlah baik, masih diperlukan perbaikan-perbaikan yang lebih. Dengan demikian penulis berharap agar tampilan progran ini pun dapat diperbaiki kemudian.

\section{DAFTAR PUSTAKA}

Ikoku, Chi. U, Natural Gas Production Engineering, John Wiley and Sons Inc.,New York 1984.

Rao S.S, Optimization Theory and Application, 2nd ed, Wiley Eastern Limited, 1989.

Mochamad Apri., Model Biaya Total Jaringan Pipa Transmisi Gas dan Optimasinya, Departemen Matematika ITB Bandung, Tugas Akhir, 2002.

Mucharam, L., Hartono, A. B, Model untuk Penentuan Diameter Optimum Pipa Transmisi Gas dengan Model Waymouth, Panhandle A, Panhandle B dan Blasius, JTM-FIKTM-ITB Vol VII No. 4, 2000

OPPINET, Final Result- March 2002, Optimization on Gas and Transmission \& Distribution Pipeline Network, Center for Research on the Application and Advancement of Mathematics- P4M ITB.

Matthews, John H., Numerical Methods for Mathematics, Science and Engineering, 2nd ed, Prentice hall, Engelwood Cllifs, New Jersey 1992.

Arsegianto, Suwono E., Apri Mochamad., Non-Linear Optimization Model for Gas Transmission System: A Case of Grissik-Duri Pipeline, SPE International, 2003. 